\title{
In vitro Study on the Antimicrobial Activity of Human Tears with Respect to Age
}

\author{
Muhammad Zahoor ${ }^{1}$, Haji Bahadar ${ }^{2,3}$, Muhammad Ayaz ${ }^{1}$, Ajmal Khan ${ }^{4}$, Muhammad Jalat Shah ${ }^{2}$ \\ ${ }^{1}$ Department of Chemistry, University of Malakand Chakdara Dir (lower), Khyber Pakhtunkhwa, Pakistan \\ ${ }^{2}$ Institute of Basic Medical Sciences, Khyber Medical University, Peshawar, Pakistan \\ ${ }^{3}$ Institute of Paramedical Sciences, Khyber Medical University, Peshawar, Pakistan \\ ${ }^{4}$ Department of Chemistry, COMSATS Institute of Information Technology, Abbottabad, Pakistan
}

\begin{abstract}
Lysozyme is present in tears and has the ability to inhibit bacterial growth. In addition, it acts as a physiological scavenger for harmful substances. In the present study, sixteen tear samples from people of different ages were evaluated for their antibacterial spectrum against selected bacterial strains (Escherichia coli, Shigella sonnei, Staphylococcus aureus, Salmonella enterica Typhi). A radial diffusion assay was used to evaluate the antibacterial potential of tear samples. To correlate the antibacterial activities of these tear samples, the concentration of lysozyme in the tear samples was also determined. Ampicillin was used as a standard drug. The zone of inhibition $(\mathrm{mm})$ was used to measure the antibacterial property of the tears. All samples showed good antibacterial activities. The tear samples of children showed antibacterial activities in the range of 4.40 5.00 $\mathrm{mm}$ inhibition zones against the selected bacterial strains. The tear samples from the young and adults showed good antibacterial potential with a zone of inhibition in the range of $3.20 \sim 4.00$ and $4.00 \sim 5.50 \mathrm{~mm}$, respectively. The tear samples from the old age group showed inhibition zones from $1.50 \sim 5 \mathrm{~mm}$. The adult tear samples showed the maximum inhibition against the selected bacterial strains among all groups. The lysozyme concentration was $1.7 \mathrm{mg} / \mathrm{mL}, 1.95 \mathrm{mg} / \mathrm{mL}, 2.13$ $\mathrm{mg} / \mathrm{mL}$, and $1.76 \mathrm{mg} / \mathrm{mL}$ for children, young, adults, and elderly, respectively. In conclusion, the tears from adults have the high inhibition potential. In addition, this data also showed that the lysozyme contents in the tear sample increased with age until 40 42 years.
\end{abstract}

Key words: Ampicillin, Antibacterial activities, Lysozyme, Tear samples

This is an Open Access article distributed under the terms of the Creative Commons Attribution Non-Commercial License (http://creativecommons.org/licenses/by-nc/4.0) which permits unrestricted non-commercial use, distribution, and reproduction in any medium, provided the original work is properly cited.

Copyright @ 2018 The Korean Society for Clinical Laboratory Science. All rights reserved.
Corresponding author: Haji Bahadar Institute of Paramedical Sciences, Khyber Medical University, Peshawar 25100, Pakistan Tel: +92-91-9217703, 9217696 Fax: +92-91-9217704

E-mail: bahadar@kmu.edu.pk

Received: February 12,2018 Revised $1^{\text {st: }}$ March 9, 2018 Revised $2^{\text {nd }}:$ March 18, 2018

Revised $3^{\text {rd }}$ : April 1, 2018

Accepted: April 2, 2018

\section{INTRODUCTION}

Human tears contain a secretory protein known as lysozyme. Tears have the ability to inhibit bacterial growth and also act as a physiological scavenger for hydrophobic and potentially harmful molecules. Tear fluid covers the entire ocular surface performing barrier function, lubrication, and antimicrobial protection. Good visual acuity is dependent on the normal tear fluid as it provides a smoother ocular surface, which is important for the optical properties of the eye $[1,2]$. Naturally, tear fluids are composed of water, mucins, oils and electrolytes.
Moreover, they contain some anti-bacterial substances protecting eyes against infections. Both in vitro and in vivo studies have confirmed the antimicrobial activity of tears by involving different mechanisms. In conjunction with blinking and reflex tearing, the tear film helps wash out the invading pathogens. The antimicrobial molecules present in tear fluid either kill the pathogen or inhibit their growth [3-5]. Tears also act as "wiper fluid", allowing the eyelids to wash the eye free of debris with every blink [6]. The eye is protected against microbes by a number of mechanisms. Among them, IgA and lysozymes play an important role. The protective role of the tear protein 
fractions has long been known. Currently, the complex nature of tear proteins has been established and at least 400 components of the tear protein fraction have been reported including specific and non-specific immunoglobulins. They provide first line of defense against infection, and seem to be more effective than the systemically produced antibodies [7]. The non-specific proteins of tear fluid including lactoferrin and lysozyme secreted by the lacrimal acinar cells have anti-bacterial activity [8].

As described previously, tears are mainly composed of water, salts, antibodies and lysozymes having both antimicrobial and immunological activities. It provides bacteriostatic as well as bactericidal properties to tear's fluid [9]. The antibacterial properties of lysozyme are well known and are also used in the food industry to limit the proliferation of lactic acid bacteria spoilage in the production of wine and beer. Similarly, it is also used to inhibit butyric acid fermentation in hard and extra hard cheeses (late blowing) caused by the outgrowth of clostridial spores [10]. An earlier report published by the Friedlland et al show that the non-lysozyme factors are mainly responsible for bactericidal properties of tears, while lysozyme is responsible for only $0.5 \%$ antibacterial activity [11]. However, later on, another study reported that lysozyme, tear specific pre-albumin, and glycoprotein are mainly responsible for antibacterial activities of tear [12]. Moreover, the important anti-bacterial role of lysozyme was reinforced by Seal and coauthors. They have reported that the antibacterial activities of tears completely disappear, when the anti-lysozyme antiserum is added with tears. Since lysozyme corresponds to $30 \%$ of the tear proteins and has been described as the main antibacterial component of tear fluid [13]. In addition, the lactoferrin has also been reported to possess antiviral activity [14].

Lysozyme (EC 3.2.1.17) is the most extensively studied antimicrobial enzyme. It exists in several mammalian secretions: milk, saliva and tears. It is a low molecular weight enzyme (14,307 Dalton) consisting 129 amino acids, which are cross-linked by four disulphide bridges.
Lysozyme has lytic activity on the $\beta(1 \rightarrow 4)$ glycosidic bond between $N$-acetyl- $D$-Glucosamine and N-acetylmuramic acid in the cell wall of bacteria, particularly in gram positive bacteria $[15,16]$. The present study aimed to evaluate the antimicrobial activity of human tears against the specified bacteria species; Escherichia coli, Shigella sonnei, Staphylococcus aureus, and Salmonella. Typhi with respect to age and lysozyme concentration.

\section{MATERIALS AND METHODS}

The Ethical Committee of the Department of Biochemistry granted approval for conducting this study. Approval was taken from the University Review Board prior to starting a collection of tear samples from volunteers (Approval NO UOM/ETC/105). All the participants included in the study were explained the nature of the study and provided informed consent in English as well as in local languages and consent was taken. All ethical principles of the World Medical Association Declaration of Helsinki were followed. Samples of human tears used in this experiment were collected from pupils of different ages. A total of 16 different tears samples were evaluated for the antimicrobial activity using the agar diffusion assay. These samples were categorized into four groups: children (1-16 years), young ( $25 \sim 28$ years), adult ( $40 \sim 42$ years) and old (60 65 years). Each group was comprised of 4 volunteers; two male and two female.

\section{Tear collection}

Using direct aspiration method, tear samples were collected by means of capillary pipettes from healthy volunteers. For children below the age of 18 years consents of their parents were taken. Tears were secreted voluntarily without using any chemical agent. From each group of volunteers the tear samples were taken on a sunny day from 9:00 to 11:00 am in the morning. The samples were collected and brought to Biochemistry Laboratory, University of Malakand for evaluation. The groups were given subjective numbers, and the detail of 
which is given as:

1. Tear samples from old group (60 65 years)

2. Tear samples from adult group (40 42 years)

3. Tear samples from young group ( $25 \sim 28$ years)

4. Tear samples from children group ( $1 \sim 16$ years)

For the preparation of standard bacterial suspension, the average number of viable Escherichia coli (ATCC25922), Shigella sonnei (ATCC 25931), Staphylococcus aureus (ATCC25923), and Salmonella Typhi (ATCC23564) organism per mL of stock solution was determined by means of surface viable counting technique. About $10^{8} \sim 10^{9}$ colony forming units (CFU) were used. A fresh stock suspension was used for every experiment.

\section{Measurement of antibacterial spectrum of tear samples}

The antibacterial spectrum of the tear samples was determined by using a radial diffusion assay as described previously [17]. In brief, under laminar flow, $25 \mathrm{~mL}$ sterilized nutrient agar solutions ( $28 \mathrm{~g} / \mathrm{L})$ were introduced into sterilized Petri dishes and allowed to cool and solidify. The sterilization of nutrient agar solutions was done at $121^{\circ} \mathrm{C}$ for $15 \mathrm{~min}$ and bacteria were grown. After that, bacteria were washed with 10 mM Tris, $\mathrm{pH} 7.4$ and plated and four wells were made in each plate using sterile cork-borer No.8 and to the well $10 \mu \mathrm{L}$ of tear sample was added and allowed to diffuse at room temperature for 2 hours. The arbitrary numbers from $1 \sim 4$ were given to the plates to differentiate among different age groups. Phosphate buffer saline (PBS) was used as negative control. Cotton swab was used for inoculation of bacterial strains. After the inoculation process, the plates were incubated at $37^{\circ} \mathrm{C}$. After 24 hours, the plates were removed from the incubator and observed for antibacterial activity. Ampicillin (10 $\mu \mathrm{g} / \mathrm{mL}$ (ThermoScientific, Oxoid, London, UK) was used as standard drug. The final concentrations of bacteria on plates were measured as a zone of inhibition in $\mathrm{mm}$.

\section{Measurement of lysozyme concentration}

The concentration of lysozyme was determined spectrophotometrically by the decrease in optical density at $450 \mathrm{~nm}$ of a Micrococcus lysodeikticus suspension in 0.1 mol/L sodium sulphate buffer at $\mathrm{pH} 7.0$ during the first minute after the addition of lysozyme solution. This procedure was carried out at $25^{\circ} \mathrm{C}$. The initial absorbance was between 1.0 1.2, therefore, dilution of the samples was carried out to get absorbance between $0.03 \sim 0.09$ as previously described [18]. The lysozyme concentration in the samples was determined by calibrating with the solution of highly purified hen egg lysozyme and the results are expressed in $\mathrm{mg} / \mathrm{mL}$ of tear samples.

\section{Statistical analysis}

Values were expressed as mean \pm SD. One way analysis of variance (ANOVA) was carried out, followed by Tukey multiple comparison test (post hoc) to determine the statistical difference $(P<0.05)$ among all groups. StatsDirect version 3.0.152 was used.

\section{RESULTS}

The effect of human tear samples against bacterial growth was evaluated and compared with the standard. The results for antibacterial activity of each age group were shown as mean \pm standard deviation (Figure 1 4). The letters A, B, C, and D were used to differentiate bacteria treated with tear samples on agar plates and are given as follows:

$\mathrm{A}=$ Tear sample + Escherichia coli

$\mathrm{B}=$ Tear sample+Shigella sonnei

$\mathrm{C}=$ Tear sample + Staphylococcus aureus

$\mathrm{D}=$ Tear sample+Salmonella Typhi

\section{Effect of tear samples on Escherichia coli}

In comparison to negative control, all tear samples significantly inhibited the growth of Escherichia coli. As indicated in Figure 1, inhibition in E. coli growth was recorded as 4.90, 3.50, 4.0, and $3.50 \mathrm{~mm}$ for children, 


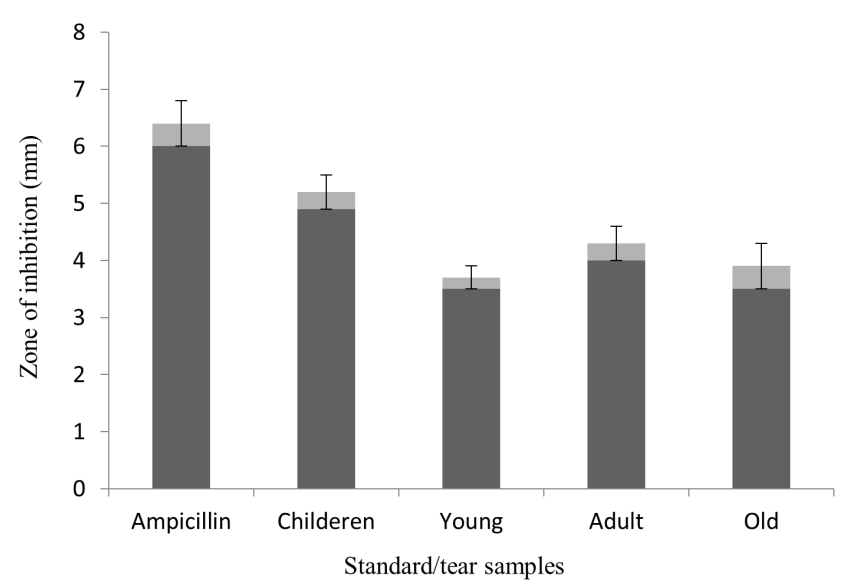

Figure 1. Antibacterial activity of tear samples against E. coli.

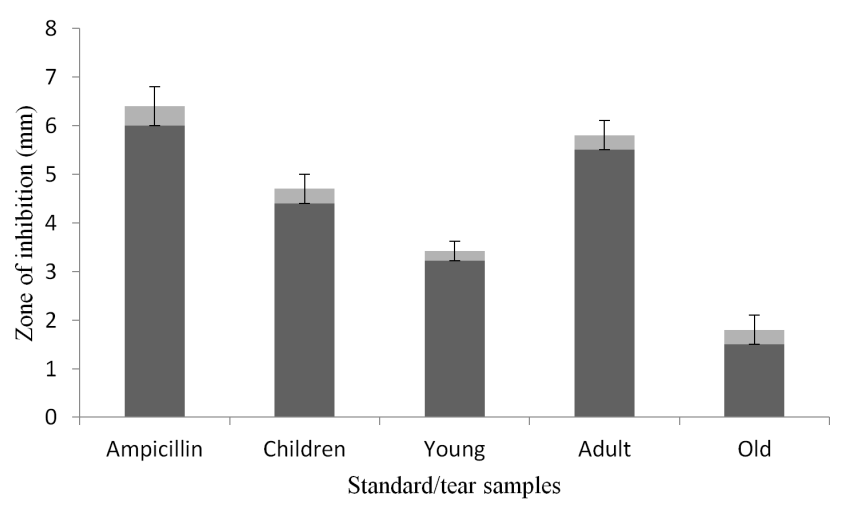

Figure 2. Antibacterial activity of tear samples against Shigella sonnei.

young, adult, and old, respectively. The standard ampicillin showed maximum bacterial inhibiting property, with a zone of inhibition $6 \mathrm{~mm}$ Figure 1.

\section{Effect of tear samples on Shigella sonnei}

The effect of tear samples on the growth of Shigella sonnei is presented in Figure 2, showing significant inhibition of bacterial growth as compared to the negative control. The standard ampicillin showed maximum bacterial inhibiting property with a zone of inhibition 6 $\mathrm{mm}$. The inhibition in Shigella sonneigrowth was as 4.40, 3.20, 5.50, and $1.50 \mathrm{~mm}$ for children, young, adult, and old, respectively.

\section{Effect of tear samples on Staphylococcus aureus}

As indicated in Figure 3, all the tear samples exerted maximum antibacterial activity against Staphylococcus

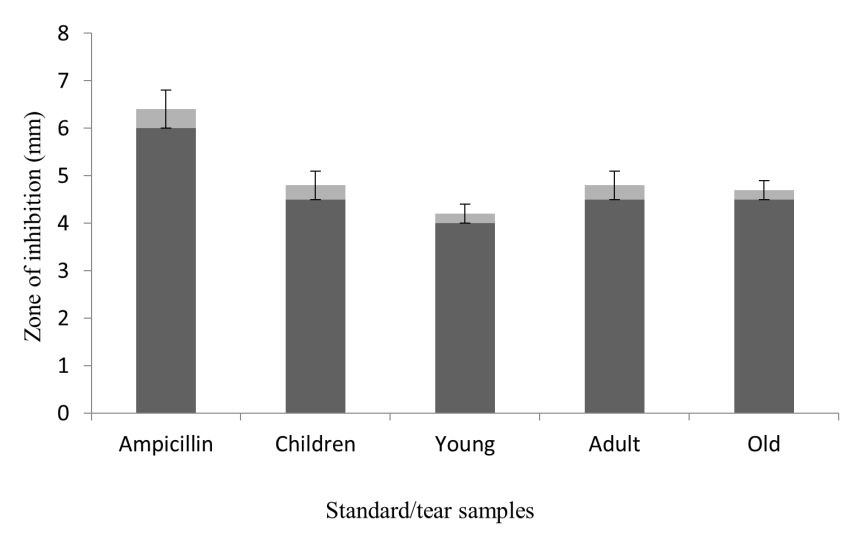

Figure 3. Antibacterial activity of tear samples against Staphylococcus aureus.

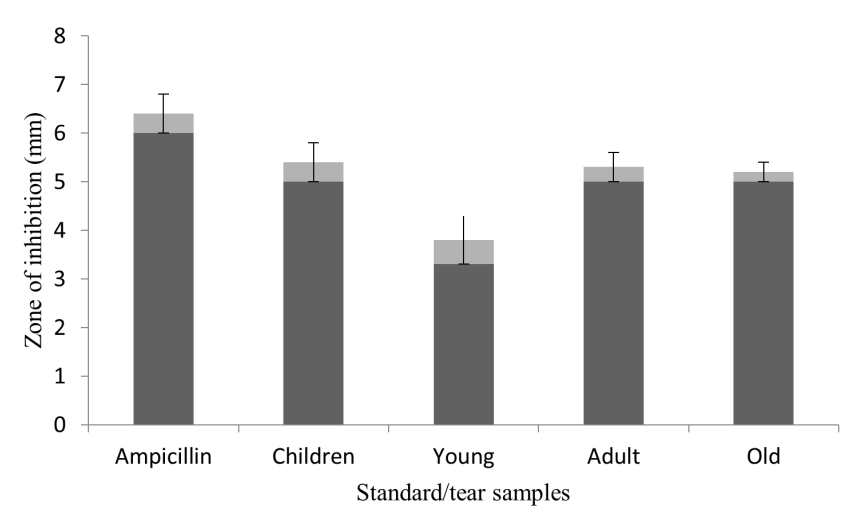

Figure 4. Antibacterial activity of tear samples against Salmonella Typhi.

aureus. The standard drug ampicillin showed significant antibacterial activity with a zone of inhibition zone $6 \mathrm{~mm}$, after 24 hours of inoculation. The inhibitory activity of tear samples was 4.50, 4.0, 4.50, and $4.50 \mathrm{~mm}$ for children, young, adult, and old, respectively.

\section{Effect of tear samples on Salmonella Typhi}

The effect of tear samples on the growth of Salmonella Typhi is presented in Figure 4. The standard ampicillin showed maximum bacterial inhibiting property, which was $6 \mathrm{~mm}$ zone of inhibition. The detail zones of inhibition were as 5.0, 3.30, 5.0, and $5.0 \mathrm{~mm}$, for children, young, adult, and old, respectively.

\section{Comparative analysis of inhibition in bacterial growth among groups}

As presented in Table 1, there was noted a significant 
Table 1. Comparison of bacterial inhibitory activity among group

\begin{tabular}{lc}
\hline \multicolumn{1}{c}{ Comparison } & $P$ value \\
\hline Children versus Young & $P<0.01$ \\
Children versus Adult & No significantly \\
Children versus Old & No significantly \\
Young versus Adult & $P<0.01$ \\
Young versus Old & No significantly \\
Adult versus Old & $P<0.05$ \\
\hline
\end{tabular}

difference between bacterial inhibitory activity between "children versus young", young versus adult" and "adult versus old" with $P<0.05$. The comparative analysis of bacterial inhibition has been made on the basis of the mean value of all bacteria against tear samples.

\section{Concentration of lysozyme in tear samples}

As presented in Figure 5, the concentration of lysozyme in the children tear samples was found in the range of 1.7 $\mathrm{mg} / \mathrm{mL}$. In the young group, lysozyme concentration was $1.95 \mathrm{mg} / \mathrm{mL}$. In adult tear samples, the concentration of lysozyme was from $2.13 \mathrm{mg} / \mathrm{mL}$, while in the old tear samples, the concentration of lysozyme was $1.76 \mathrm{mg} / \mathrm{mL}$.

\section{DISCUSSION}

In the present study, sixteen different tear samples of different age groups were evaluated for their antibacterial activities against four different strains of bacteria. Tear samples were collected from children, young, adult, and old persons. All these samples were categorized in four groups as described above. The results showed that these tear samples possess potential antibacterial activities against gram positive and gram negative bacterial strains. The standard ampicillin showed maximum antimicrobial activity, which was used as a reference. In literature the antibacterial and antifungal spectrum of tears has been investigated. However, the antibacterial spectrum of human tear with respect to age has not been evaluated, and this is the first report of antibacterial activity of tears with respect to age. According to Blaker et al., the action of tears against fungal infection would complement the numerous bacterial defenses already described for the eye

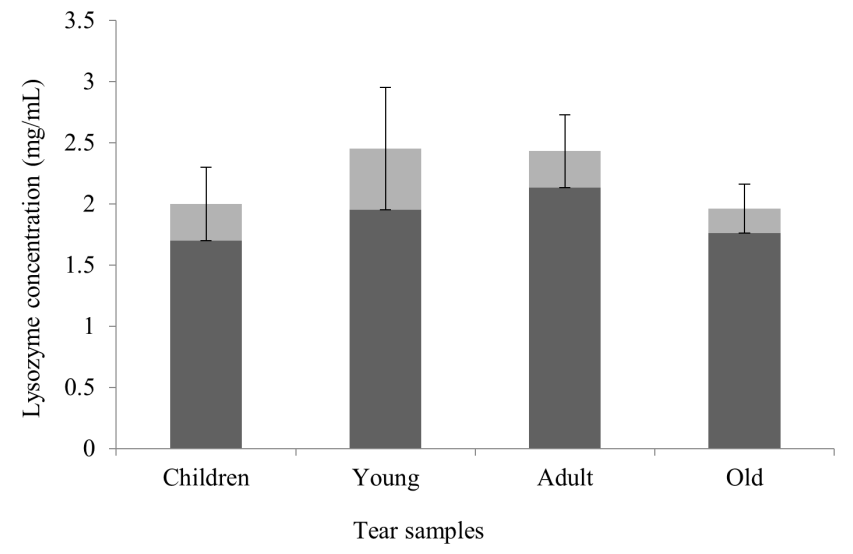

Figure 5. Lysozyme concentration in different tear samples.

and would be valuable in the mouth, trachea, and other locations [19]. Human tear lipocalin acts as a scavenger for oxidative-stress-induced lipid peroxidation products in a cell culture system [20,21]. In the first group, tear samples of children showed antimicrobial activity as $\mathrm{D}>\mathrm{A}>\mathrm{C}>\mathrm{B}$. The tear samples from children showed significant inhibition against gram negative bacteria Salmonella Typhi. The children tear samples also showed inhibition against Escherichia coli, Staphylococcus aureus, and Shigella sonnei. Moreover, the lysozyme concentration in children tear samples was $1.7 \sim 1.99 \mathrm{mg} / \mathrm{mL}$. The trend of antibacterial activities of tear samples from young were as; $\mathrm{C}>\mathrm{A}>\mathrm{D}>\mathrm{B}$. The young tear samples showed maximum inhibition against gram positive bacteria, Staphylococcus aureus, Escherichia coli, Salmonella. Typhi and Shigella sonnei. The young's tear samples have lysozyme concentration $1.95 \sim 2.10 \mathrm{mg} / \mathrm{mL}$. The antibacterial potential of tear samples from adult were as; $\mathrm{B}>\mathrm{D}>\mathrm{C}>\mathrm{A}$. The adult tear samples showed significant inhibition against gram positive bacteria Shigella sonnei and zone of inhibition was found almost similar to standard drug ampicillin. Moreover, the adult tear samples also showed significant inhibition against other bacterial strains such as, Salmonella Typhi, Staphylococcus aureus and Escherichia coli. The lysozyme concentration in adult tear samples was $2.13 \sim 2.28 \mathrm{mg} / \mathrm{mL}$. The old tear samples showed antibacterial activities as $\mathrm{D}>\mathrm{C}>\mathrm{A}>\mathrm{B}$. The tear samples from old showed significant inhibition against gram negative bacteria Salmonella Typhi, Staphylococcus 
aureus, Escherichia coli and Shigella sonnei. The tear samples from old have lysozyme concentration 1.76 1.88 $\mathrm{mg} / \mathrm{mL}$. The lower antibacterial activity of tear samples from old as compared to other groups was due the less concentration of lysozyme in old tear samples. According to Seal et al., lysozyme is the main antibacterial component of tears. Lysozyme breaks the $\beta(1 \rightarrow 4)$ glycosidic bond between $N$-acetyl- $D$-Glucosamine and $N$-acetylmuramic acid in the cell wall of bacterial species, particularly in gram positive microorganisms $[13,16]$. In our study, the maximum concentration of lysozyme was found in adult tears samples, followed by tear samples of the young group. The concentration of lysozyme was higher in children tear samples as compared to old aged person. It has been reported that the tear lysozyme level is not affected by sex, but affected slightly with age. Moreover, previously variation has been reported in lysozyme concentration in the morning and evening [18, 22]. After comparing the antibacterial activities of all groups, it is concluded that the highest concentration of lysozyme is responsible for high inhibition zone against selected bacteria, exhibited by adult tear samples. If the antibacterial spectrum of the rest of the samples is correlated with the lysozyme concentration, the results are in close agreement with each other. Although in the young person's tear samples, the lysozyme concentration is high in fractions $(0.1 \mathrm{mg} / \mathrm{mL})$ from the children's tear samples. That's why the results are not drastically different. The antibacterial spectrum of young and children group are almost same. In the present study, tear samples from all age groups showed significant antibacterial activities. The adult's tear samples showed maximum inhibition potential against selected bacterial strains. These extraordinary activities were due to the high lysozyme concentration in adult tear samples. Comparatively the young tear samples were highly potent against the selected bacterial strains as compared to old tear samples. Moreover, with respect to gender, there was observed no difference either in term of antibacterial activity or lysozyme concentration.
Acknowledgements: All the authors are thankful to Higher Education Commission of Pakistan for providing funds and research facilities in our laboratory.

Conflict of interest: None

\section{REFERENCES}

1. Bron A, Tiffany J, Gouveia S, Yokoi N, LW Voon. Functional aspects of the tear film lipid layer. Exp Eye Res. 2004;78:347-360.

2. Goto E, Ishida R, Kaido M, Dogru M, Matsumoto Y, Kojima T. Optical aberrations and visual disturbances associated with dry eye. Ocul Surf. 2006;4:207-213.

3. Fleiszig SMJ, Kwong MSF, Evans DJ. Modification of Pseudomonas aeruginosa interactions with corneal epithelial cells by human tear fluid. Infect Immun. 2003;71:3866-3874.

4. Kwong MSF, Evans DJ, Ni M, Cowell BA, Fleiszig SMJ. Human tear fluid protects against Pseudomonas aeruginosa keratitis in a murine experimental model. Infect Immun. 2007;75:23252332.

5. McNamara NA, Andika R, Kwong M, Sack RA, Fleiszig SMJ. Interaction of Pseudomonas aeruginosa with human tear fluid components. Curr Eye Res. 2005;30:517-525.

6. Cassel G, Billing M, et al. Eye book. Baltimore: Johns Hopkins Press ; 1998.

7. Arnold R, Brewer M, Gauthier J. Bactericidal activity of lactoferrin: sensitivity of a variety of microorganisms. Infect Immun. 1980;28:893-898.

8. Gillette T, Allansmith M. Lactoferrin in human ocular tissues. Am J Ophthalmol. 1980;90:30-37.

9. Schnetler R, Gillan W, Koorsen G. Immunological and antimicrobial molecules in human tears a review and preliminary report. S Afr Optom. 2012;71:123-132.

10. Brasca M, Morandi S, Silvetti T, Rosi V, Cattaneo S. Pellegrino L. Different analytical approaches in assessing antibacterial activity and the purity of commercial lysozyme preparations for dairy application. Molecules. 2013;18:6008-6020.

11. Friedland B, Anderson D, Forster R. Non-lysozyme antibacterial factor in human tears. Am J Ophthalmol. 1972;74:52-59.

12. Selsted M, Martinez R. Isolation and purification of bactericides from human tears. Exp Eye Res. 198;34:305-318.

13. Seal D, Mackie I, Coakes R, Farooqi B. Quantitative tear lysozyme assay: a new technique for transporting specimens. Br J Ophthalmol. 1980;64:700-704.

14. Van der Strate, BWA, Beljaars L, Molema G, Harmsen M C, Meijer DKF. Antiviral activities of lactoferrin. Antiviral Res. 2001;52: 225-239.

15. Silvetti, T, Brasca M, Lodi R, Vanoni L, Chiolerio F, Groot M.D et al. Effects of lysozyme on the microbiological stability and organoleptic properties of unpasteurized beer. J Inst Brew. 2010;116:33-40.

16. Tirelli A. De Noni I. Evaluation of lysozyme stability in young red wine and model systems by a validated HPLC method. Food Chem. 2007;105:1564-1570.

17. Papareddy P, Kalle M, Bhongir RKV, Mörgelin M, Malmsten M, Schmidtchen A. Antimicrobial Effects of Helix D-derived 
Peptides of Human Antithrombin III. J Biol Chem. 2014;289: 29790-29800.

18. Mackie I, Seal D. Quantitative tear lysozyme assay in units of activity per microlitre. Br J Ophthalmol. 1976;60:70-74.

19. Blaker M, Kock K, Ahlers C, Buck F, Schmale, H. Molecular cloning of human von Ebner's gland protein, a member of the lipocalin superfamily highly expressed in lingual salivar glands. Biochim Biophys Acta 1993;1172:131-137.

20. Lechner M, Wojnar P, Redl, B. Human tear lipocalin acts as an oxidative-stress-induced scavenger of potentially harmful lipid peroxidation products in a cell culture system. Biochem. 2001;356(Pt 1):129-135.

21. Tutt R, Bradley A, Begley C, Thibos L. Optical and visual impact of tear break-up in human eyes. Invest. Ophthalmol Vis Sci. 2000;41:4117-4123.

22. Sen DK, Sarin GS. Biological variations of lysozyme concentration in the tear fluids of healthy persons. Brit J Ophthalmol. 1986;70:246-248. 